\title{
Very Low Carbohydrate Diet Effect on Modified Glasgow Prognostic Score: A Randomized Controlled Trial on Stage-IV Colorectal Adenocarcinoma Patients
}

\author{
Vicky Sumarki Budipramana ${ }^{1}$, Fransiscus Arifin ${ }^{2}$
}

\author{
*Corresponding author: \\ Vicky Sumarki Budipramana, MD \\ Digestive Surgery Division \\ Department of Surgery \\ Faculty of Medicine \\ Universitas Airlangga \\ Dr. Soetomo General Hospital \\ Jl. Mayjen Prof. Dr. Moestopo 47, \\ Surabaya, 60132, Indonesia \\ E-mail: vickysbudi@gmail.com
}

\author{
'Division of Digestive Surgery, Department of Surgery, Dr. Soetomo Genetral Hospital, \\ Universitas Airlangga, Surabaya, Indonesia \\ 2Department of Surgery, Dr.Soetomo General Hospital, Universitas Airlangga \\ Surabaya-Indonesia
}

\section{ABSTRACT}

Background: The stage-IV Colorectal adenocarcinoma patients who cannot be treated with any conventional cancer treatment (surgery, chemotherapy, or radiotherapy) belong to the best supportive care group. Very low carbohydrate diet reduces the glucose supply to the cancer cells through the specific metabolic pathway called the Warburg effect. The cancer cell may "starve" and limit the growth that can be measured by the reduction of the systemic inflammation reaction using modified Glasgow Prognostic Score (mGPS). This study aimed to prove that a very low carbohydrate diet may reduce the systemic inflammation score in adenocarcinoma patients with best supportive care.

Methods: Randomized controlled trial of two groups, 12 participants in one groupwere given the diet of very low carbohydrate for three weeks, and the other12 participants in control group were given normal diet. All of the participants were given a diet with the amount of calorie according to their respective needs.We measured serum albumin and $C$ Reactive Protein (mGPS) before and after the intervention.

Results: We found statistically significant reduction of modified Glasgow Prognostic Score in the intervention group.

Conclusion: The growth of the stage-IV colorectal adenocarcinoma measured by the systemic inflammation indicators was reduced by giving very low carbohydrate diet.

Key words: best supportive care, stage IV colorectal adenocarcinoma, systemic inflammation, very low carbohydrate diet

\section{INTRODUCTION}

There are specific metabolic pathways on cancer cell in utilizing substrate to produce energy, which is known as the Warburg effect. Warburg effect is an aerobic glycolysis in which the cancer cells convert glucose to ATP without Kreb cycle, so the energy product is inefficient. These cancer cells must use more glucose to produce the same amount of energy as normal cells do. Furthermore, 
cancer cells can only use glucose as the source of energyand cannot use other substrates, such as ketone bodies to produce ATP. Many studies have shown that cancer cells have an upregulation of glucose receptors and because of it, almost exclusively dependent on glucose as the source of energy. The shift of the source of energy from glucose to ketone bodies can be tolerated by normal cells but not by cancer cells $(1,2,3)$. Reducing glucose intake and switching caloric source to other nutrients may limit the growth of cancer cells $(4,5,6,7)$.

Very low carbohydrate diet is defined as isocaloric diet with most of the calories based on fat, and normal intake of protein. Most studies use the 1:4 ratio, in which the contribution of carbohydrate was one-fifth of the total caloric requirement. The cells are then forced to use ketone bodies as the main fuelbecause glucose supply is reduced and ketone bodies are readily available $(3,8,9)$. We can clinically find ketone bodies excreted in the urine. This diet will reduce glucose supply to the cancer cells and prevent the cancer cellsfrombeing metabolically active. The reduction of glucose intake will decrease the systemic inflammatory response triggered by the cancer growth $(10,11,12)$. A preliminary study by Schmidt et al showed that the diet is safe without severe side effects and can also improve the quality of life of advanced stage cancer patients who no longer receive conventional therapy (13).

Inflammation can be induced by carcinogenesis by the stimulation of proinflammatory mediators such as TNF alpha, IL-6, and IL-10. Modified Glasgow Prognostic Score has been validated as a measurement of systemic inflammation. This score is also correlated well with the overall survival of many cancers, including gastric, prostate, and colorectal adenocarcinoma (14-19). It is easy to utilize only two laboratory measurements, which are the serum level of albumin and C Reactive Protein. We use this measurement as an indicator of systemic inflammation and as a prognostic factor of survival.

\section{METHODS}

\section{Design}

This was a randomized controlled trial (RCT) without blinding conducted on the patients with colorectal adenocarcinoma with the best supportive care.

\section{Time and location}

The research was conductedat Dr. Soetomo General Hospital Surabaya from March to October 2017.

\section{Sampling and sample size}

We recruited 24 stage-IV colorectal adenocarcinoma patients with the best supportive care consecutively at Dr. Soetomo Hospital between March and October 2017 who met our inclusion and exclusion criteria and randomly devidedinto thetreatment group and the control group.

\section{The inclusion criteria are as follows}

Diagnosed pathologically as stage-IV adenocarcinoma of the colon or rectum, thedecision made by the attending physician (digestive surgery consultant) that the patient belonged to the best supportive care group, aged more than 17 years and be able to give consent, Karnofsky score $>50 \%$ or ECOG performance status $\leq 2$, no clinical signs of infectionbased on one or more ofcriteria: fever, leucocytosis and local infectionon clinically observable body region, AST(SGOT) less than 2 times normal limit, ALT(SGPT) less than 2 times normal limit, Creatinine serum less than 1,5 normal limit, for womennot pregnant, able and willing to sign informed consent document.

\section{The exclusion criteria are as follows}

Diabetes Mellitus, Fat intolerance, Chronic corticosteroid use, severemalnourished patients or patients with cancer cachexia, patients with significant comorbid such as symptomatic congestive heart failure, unstable angina pectoris, cardiac arrhythmia, psychosis or other mental problems hindering the ability toobey the study protocol.

The sample size was determined using Iceberg Sim version 4.0.3 Beta Clinical Trial Simulator with the parameter in fig. 1 . The result was 24 samples, 12 in the control group and the other 12 in the intervention group, with power $80 \%$ and alpha $1,4 \%$.

\section{Study protocol}

The samples (Serum Albumin and C Reactive Protein) were taken on the $1^{\text {st }}$ and the $21^{\text {st }}$ day. The calorie requirementfor the two groups was calculated according to the weight of the patient and the daily composition of the diet was determined by the qualified hospital dietitian. The composition of the diet on the Very Low Carbohydrate Diet group was 1:4 ratio, in which the contribution of carbohydrate was one-fifth and protein plus fat was four-fifth from the total calorie 


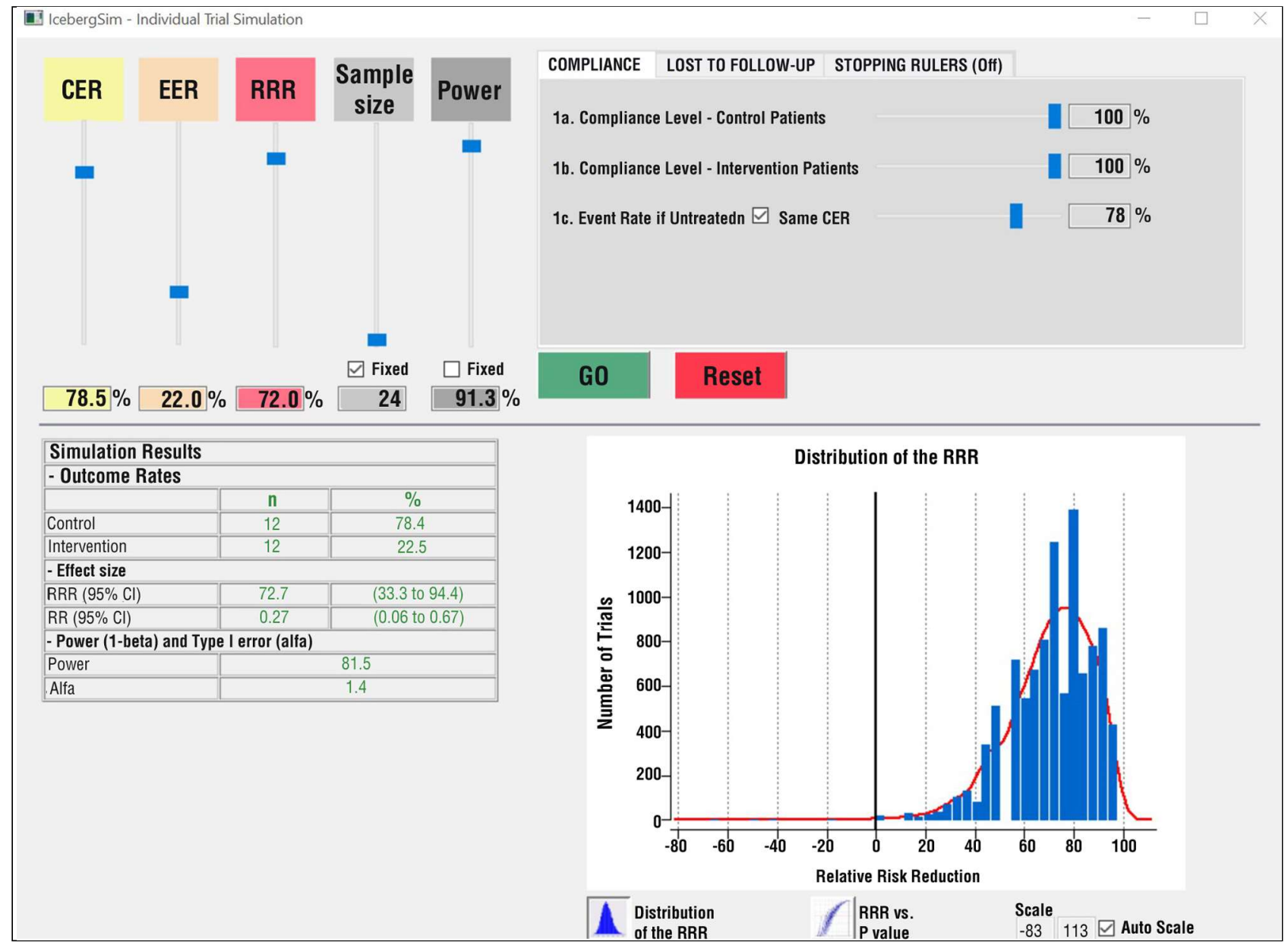

Figure 1 - Output from Iceberg Sim version 4.0.3 Beta

requirement. While on the control group the calorie and composition of the diet weremeasured in the same way as those of the common patients in the hospital. As long as the patients were included in the study, the patients were isolated in the hospital to ensure that the patients complied with the diet protocol (fig. 2).

\section{Data analysis}

We analyze the data using paired t-test on SPSS.

\section{RESULTS}

Our sample includes 14 females (58\%) and 10 males $(42 \%)$ divided into intervention and control groups. In the intervention group, there were 5 women and 7 men, and in the control group, there were 9 females and 3 males (table 1). Based on age, most samples were between $40-65$ years old $(79,2 \%)$ (table 2$)$.

\section{Secondary variables distribution before intervention}

We measured the secondary variables to evaluate the impact on very low carbohydrate diet in liver, renal, and hematologic variables (table 3). Most variables were within normal limit, and all samples met the inclusion criteria.

\section{Primary variables (CRP and Albumin) before intervention}

The CRP of the control group was higher than that of

Table 1 - Sample sex distribution

\begin{tabular}{lcccc}
\hline Sex & Intervention & Control & Total & $\%$ \\
\hline Male & 7 & 3 & 10 & 42 \\
\hline Female & 5 & 9 & 14 & 58 \\
\hline & 12 & 12 & 24 & 100 \\
\hline
\end{tabular}

Table 2 - Sample age distribution

\begin{tabular}{lcccc}
\hline & Intervention & Control & Total & $\%$ \\
\hline$<40$ Years & 0 & 2 & 2 & 8,3 \\
\hline $40-65$ Years & 11 & 8 & 19 & 79,2 \\
\hdashline 65 Years & 1 & 2 & 3 & 12,5 \\
\hline & 12 & 12 & 24 & 100 \\
\hline
\end{tabular}




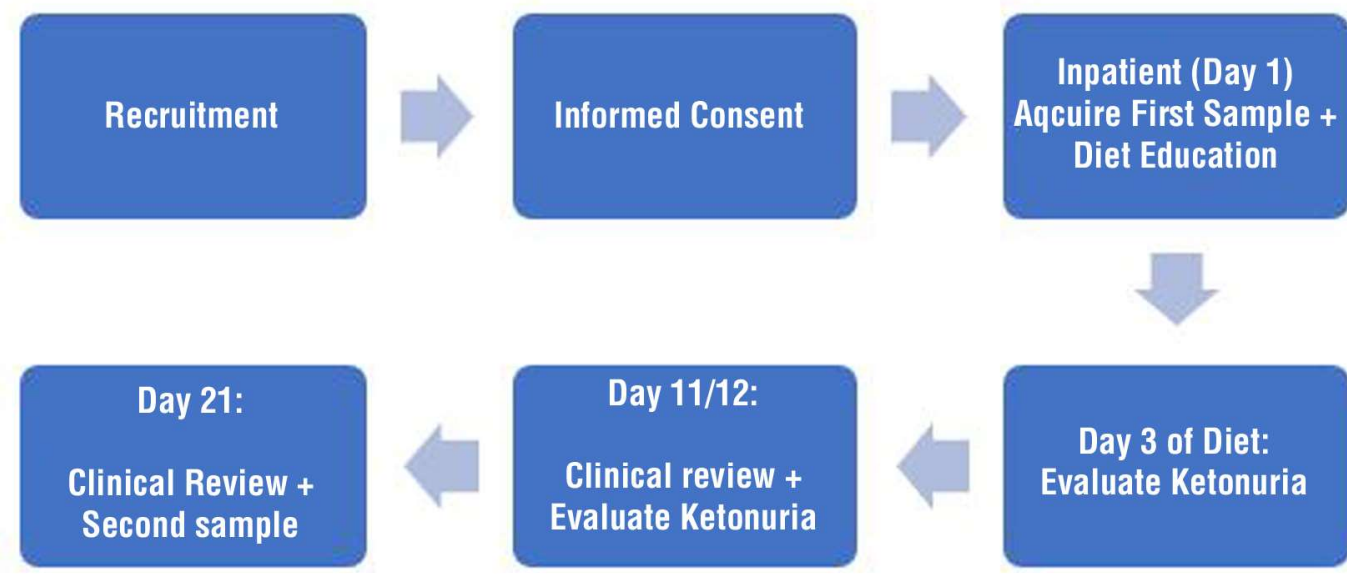

Data Analysis and

Reporting
Figure 2 - Study protocols the intervention group, while the mean of albumin level of the control group was lower than the intervention group (table 4).

Secondary Variables Distribution after Intervention

We found a rise in mean SGPT level on the intervention group, while there was no change in the control group (table 5).

\section{Primary variables (CRP and Albumin) after intervention}

The mean CRP level in the intervention group was lower than that in the control group, while the albumin level in the intervention group was higher than that in the control group (table 6).

\section{Modified Glasgow prognostic score before and after intervention}

There was a reduction in MGPS after intervention in the intervention group, while in the control group, the score increased (table 7).

We tested the normality of mGPS distribution usingKolgomorov-Smirnov, and the test showed normal distribution. On the paired T-test, the result showed that therewas a significant difference in the mean of mGPS in both groups (table 8).
Table 3 - Central tendency of secondary variables

\begin{tabular}{lcccccc}
\hline Variable & \multicolumn{3}{c}{ Intervention } & \multicolumn{3}{c}{ Control } \\
\hline & Min & Max & Mean & Min & Max & Mean \\
\hline Hb & 8,9 & 13,5 & 11,7 & 9 & 12,4 & 10,9 \\
\hdashline Leukosit & 4,62 & 19 & 9,3 & 7,5 & 19,1 & 12,3 \\
\hline SGPT & 10 & 58 & 27 & 11 & 27 & 19 \\
\hline SGOT & 16 & 66 & 30 & 18 & 66 & 28 \\
\hdashline BUN & 6 & 20 & 12 & 7 & 30 & 17 \\
\hdashline Creatinine Serum & 0.58 & 1.2 & 0.86 & 0.4 & 1.1 & 0,7 \\
\hline
\end{tabular}

Table 4 - Central tendency of albumin and CRP before intervention

\begin{tabular}{lrrrrrr}
\hline Variable & \multicolumn{3}{c}{ Intervention } & \multicolumn{3}{c}{ Control } \\
\hline & Min & Max & Mean & Min & Max & Mean \\
\hline CRP & 0,1 & 16 & 6,2 & 7.5 & 22 & 16,8 \\
\hdashline Albumin & 3,2 & 4,5 & 3,7 & 2,1 & 3,9 & 3,0 \\
\hline
\end{tabular}

Table 5 - Central tendency of secondary variables after intervention

\begin{tabular}{lcrrrrr}
\hline Variable & \multicolumn{3}{c}{ Intervention } & \multicolumn{3}{c}{ Control } \\
\hline & Min & Max & Mean & Min & Max & Mean \\
\hline CRP & 0,1 & 16 & 6,2 & 7.5 & 22 & 16,8 \\
\hline Hb & 8,9 & 14,4 & 11,2 & 8,8 & 12,5 & 11 \\
\hline Leukocyte & 6,29 & 17,5 & 10,1 & 7,8 & 40 & 8,5 \\
\hline SGPT & 12 & 125 & 37 & 14 & 23 & 19 \\
\hline SGOT & 15 & 206 & 46 & 12 & 65 & 28 \\
\hline BUN & 0.9 & 23 & 14,3 & 7 & 29 & 17,7 \\
\hdashline & 0.5 & 1.1 & 0,8 & 0,3 & 1 & 0,69 \\
\hline
\end{tabular}


Table 6 - Central tendency of albumin and CRP after intervention

\begin{tabular}{lcrrrrr}
\hline Variable & \multicolumn{3}{c}{ Intervention } & \multicolumn{3}{c}{ Control } \\
\hline & Min & Max & Mean & Min & Max & Mean \\
\hline CRP & 0,1 & 9 & 4,17 & 9 & 26 & 18,2 \\
\hdashline Albumin & 3,1 & 4,6 & 3,8 & 2,3 & 3,8 & 2,9 \\
\hline
\end{tabular}

Table 8 - T-test results of mGPS in intervention and control group

\begin{tabular}{lcccc}
\hline Group & Pairs & $\mathbf{t}$ & $\mathbf{d f}$ & $\mathbf{p}$ \\
\hline Intervention & mGPS Pre and Post & 1,820 & 11 & $0,043^{*}$ \\
\hdashline Control & mGPS Pre and Post & $-1,915$ & 11 & $0,04^{*}$ \\
\hline
\end{tabular}

* significant in the level of $95 \%$

Table 7 - mGPS beforeand after Intervention

\begin{tabular}{ccccccc}
\hline & \multicolumn{2}{c}{ Intervention } & Change & \multicolumn{2}{c}{ Control } & Change \\
\hline & Pre & Post & & Pre & Post & \\
\hdashline$\ldots$ mGS & 0,58 & 0,17 & $-0,41$ & 1,5 & 1,75 & 0,25 \\
\hline
\end{tabular}

\section{DISCUSSION}

Very low carbohydrate diet is the diet that shifts the main source of energy from glucose to ketone $(3,8,9)$. The diet is extensively used in pediatric epilepsy cases to reduce seizures, $(3,20,21)$ and also beneficial to brain tumor cases $(22,23)$. Carcinogenesis and cancer growth are connected to local and systemic inflammation (2426). The reduction in glucose consumption will also reduce systemic inflammation (10-12).

Our data showed that very low carbohydrate diet reduced systemic inflammation as measured with mGPS on colorectal adenocarcinoma patients with Best Supportive Care. This reduction did not happen in the control groupbut instead, there was an increase of the systemic inflammatory reaction. The best supportive care samples were recruited in this study because there was no other treatment such as surgery, chemotherapy, or radiotherapy given to the patient, so the changes in themGPSwere mainly because of the intervention we gave.Pantano et al showed that in cancer patients with palliative care, higher mGPS score was related to more aggressive cancer and worse survival (27). Other studies also showed that mGPSpredicted survival in colorectal cancer patients who underwent curative hepatectomy (28). mGPS also predicts earlier mortality in colorectal cancer with peritoneal carcinomatosis in cancer patients who undergo chemotherapy (29).

Our measurements of secondary variables which monitored the liver, renal, and hematologic function showed that the diet increased SGOT and SGPT, although the overall change was not statistically significant. Nevertheless, one patient showed more than twofold increase at the end of the study. Ballaban-Gil et al found that this diet increased liver function test, but a review by Lin et al after that study showed that liver toxicity happened because of concurrent drug given to the study population
$(30,31)$. Ketonuria was measured to ensure that the patients in the treatment group had already been able to use ketone as the source of energy and all of them positive for ketonuria on the $3^{\text {th }}$ and the $21^{\text {st }}$ day. We cannot do this study formore than 21 days because we have found it impossible to isolate the patients in the hospital longer than that period.

Renal function did not show significant change before and after the diet.The other study in 317 children showed that this diet may increase the incidence of urinary tract stone, with the frequency of less than $5 \%(21)$.

\section{CONCLUSION}

From this study, it could be concluded that very low carbohydrate diet given for three weeks increased the albumin level and reduced CRP level in stage-IV colorectal adenocarcinoma patients with best supportive care. Very low carbohydrate diet also reduced Modified Glasgow Prognostic Score used as the indicator for systemic inflammation in these patients. Moreover, very low carbohydrate diet apparently did not cause significant effect in liver and renal function after three weeks in stage-IV colorectal adenocarcinoma patients with best supportive care.

\section{Ethical clearance}

This RCT is cleared ethically by the Ethics Committee of Dr. Soetomo Hospital Surabaya Indonesia with ethical clearance letter no. 293/ Panke.KKE/IV/2017.

\section{Conflict of interest}

The authors declare that they have no conflict of interest. 


\section{REFERENCES}

1. Klement RJ. Calorie or carbohydrate restriction? The ketogenic diet as another option for supportive cancer treatment. Oncologist 2013;18(9):1056.

2. Otto C, Kaemmerer U, Illert B, Muehling B, Pfetzer N, Wittig R, et al. Growth of human gastric cancer cells in nude mice is delayed by a ketogenic diet supplemented with omega- 3 fatty acids and mediumchain triglycerides. BMC cancer. 2008;8:122.

3. Freeman JM, Kossoff EH, Hartman AL. The ketogenic diet: one decade later. Pediatrics. 2007;119(3):535-43

4. Seyfried TN, Shelton LM. Cancer as a metabolic disease. Nutrition \& metabolism. 2010;7:7.

5. Seyfried TN. Cancer as a mitochondrial metabolic disease. Frontiers in cell and developmental biology. 2015;3:43.

6. Hu T, Mills KT, Yao L, Demanelis K, Eloustaz M, Yancy WS, Jr., et al. Effects of low-carbohydrate diets versus low-fat diets on metabolic risk factors: a meta-analysis of randomized controlled clinical trials. American journal of epidemiology. 2012;176 Suppl 7(Suppl 7): S44-54.

7. Yoshida GJ. Metabolic reprogramming: the emerging concept and associated therapeutic strategies. J Exp Clin Cancer Res. 2015;34 111. doi: 10.1186/s13046-015-0221-y.

8. Hartman AL, Vining EP. Clinical aspects of the ketogenic diet Epilepsia. 2007;48(1):31-42.

9. Paoli A, Bosco G, Camporesi EM, Mangar D. Ketosis, ketogenic diet and food intake control: a complex relationship. Front Psychol. 2015;6:27

10. Hussain TA, Mathew TC, Dashti AA, Asfar S, Al-Zaid N, Dashti HM Effect of low-calorie versus low-carbohydrate ketogenic diet in type 2 diabetes. Nutrition. 2012;28(10):1016-21

11. Dashti HM, Al-Zaid NS, Mathew TC, Al-Mousawi M, Talib H, Asfar SK, et al. Long term effects of ketogenic diet in obese subjects with high cholesterol level. Molecular and cellular biochemistry. 2006;286(1-2):1-9.

12. Westman EC, Yancy WS, Jr, Mavropoulos JC, Marquart M, McDuffie $J R$. The effect of a low-carbohydrate, ketogenic diet versus a lowglycemic index diet on glycemic control in type 2 diabetes mellitus. Nutr Metab (Lond). 2008;5:36.

13. Schmidt M, Pfetzer N, Schwab M, Strauss I, Kammerer U. Effects of a ketogenic diet on the quality of life in 16 patients with advanced cancer: A pilot trial. Nutrition \& metabolism. 2011;8(1):54.

14. Eren T, Burcu B, Tombalak E, Ozdemir T, Leblebici M, Ozemir IA, et al. Clinical Significance of the Glasgow Prognostic Score for Survival after Colorectal Cancer Surgery. Journal of gastrointestinal surgery official journal of the Society for Surgery of the Alimentary Tract. 2016;20(6):1231-8

15. Lin MS, Huang JX, Yu H. Prognostic significance of Glasgow prognostic score in patients with stage II colorectal cancer International journal of clinical and experimental medicine. 2015;8(10):19138-43.
16. Petrelli F, Barni S, Coinu A, Bertocchi P, Borgonovo K, Cabiddu M, et al. The Modified Glasgow Prognostic Score and Survival in Colorectal Cancer: A Pooled Analysis of the Literature. Reviews on recent clinical trials. 2015;10(2):135-41.

17. Adachi T, Hinoi T, Hattori M, Egi H, Shimomura M, Saito $Y$, et al. The modified Glasgow prognostic score for early mortality in patients with synchronous peritoneal carcinomatosis from colorectal cancer. Surgery today. 2015;45(11):1396-403.

18. Choi KW, Hong SW, Chang YG, Lee WY, Lee B, Paik IW, et al. Inflammation-based score (Glasgow prognostic score) as an independent prognostic factor in colorectal cancer patients. Annals of surgical treatment and research. 2014;86(6):309-13.

19. Nozoe T, Matono R, ljichi H, Ohga T, Ezaki T. Glasgow Prognostic Score (GPS) can be a useful indicator to determine prognosis of patients with colorectal carcinoma. International surgery. 2014; 99(5):512-7.

20. Danial NN, Hartman AL, Stafstrom CE, Thio LL. How does the ketogenic diet work? Four potential mechanisms. Journal of child neurology. 2013;28(8):1027-33

21. Suo C, Liao J, Lu X, Fang K, Hu Y, Chen L, et al. Efficacy and safety of the ketogenic diet in Chinese children. Seizure. 2013;22(3):174-8.

22. Zhou W, Mukherjee P, Kiebish MA, Markis WT, Mantis JG, Seyfried TN. The calorically restricted ketogenic diet, an effective alternative therapy for malignant brain cancer. Nutrition \& metabolism. 2007:4:5.

23. Meidenbauer JJ, Mukherjee P, Seyfried TN. The glucose ketone index calculator: a simple tool to monitor therapeutic efficacy for metabolic management of brain cancer. Nutrition \& metabolism. 2015;12:12.

24. Aggarwal BB, Sung B. The relationship between inflammation and cancer is analogous to that between fuel and fire. Oncology. 2011; 25(5):414-8.

25. Chow MT, Moller A, Smyth MJ. Inflammation and immune surveillance in cancer. Seminars in cancer biology. 2012;22(1):23-32.

26. Janakiram NB, Rao CV. The role of inflammation in colon cancer. Advances in experimental medicine and biology. 2014;816:25-52.

27. Pantano NdP, Paiva BSR, Hui D, Carlos Eduardo Paiva. Validation of the Modified Glasgow Prognostic Score in Advanced Cancer Patients Receiving Palliative Care. J Pain Symp Manag. 2015:1-8.

28. Nakagawa K, Tanaka K, Nojiri K, Kumamoto T, Takeda K, Ueda M, et al. The Modified Glasgow Prognostic Score as a Predictor of Survival After Hepatectomy for Colorectal Liver Metastases. Annals of surgical oncology. 2014;21:1711-18.

29. Adachi T, Hinoi T, Hattori M, Egi H, Shimomura M, Saito Y, et al. The modified Glasgow prognostic score for early mortality in patients with synchronous peritoneal carcinomatosis from colorectal cancer. Surg Today. 2015;45(11):1396-403. Epub 2014 Nov 28.

30. Ballaban-Gil K, Callahan C, O'Dell C, Pappo M, Moshe S, Shinnar S. Complications of the ketogenic diet. Epilepsia. 1998;39(7):744-8.

31. Lin A, Turner Z, Doerrer SC, Stanfield A, Kossoff EH. Complications During Ketogenic Diet Initiation: Prevalence, Treatment, and Influence on Seizure Outcomes. Pediatric neurology. 2017;68:35-9. 